\title{
Treatment of electrical burns by single debridement followed by free-flap coverage: How important is timing?
}

\author{
Christopher J Thomson MD', Duncan AG Miles $\mathrm{MD}^{2}$, John Beveridge $\mathrm{MD}^{3}$, Peter S Chang $\mathrm{MD}^{4}$
}

CJ Thomson, DAG Miles, J Beveridge, PS Chang. Treatment of electrical burns by single debridement followed by free-flap coverage: How important is timing? Can J Plast Surg 2004;12(1):35-36.

BACKGROUND: High-voltage electrical burns involving the extremities may cause marked loss of skin and subcutaneous tissue exposing underlying bone and tendon. Treatment of electrical burns has historically involved serial debridement with late wound closure. Success has been reported with the use of microvascular free-flap transfer within three days of injury.

OBJECTIVE: Seven patients with severe high-voltage electrical burns are presented. The application and timing of microvascular free-flap coverage is discussed.

RESULTS: Six of the seven patients achieved successful healing with the free flaps.

CONCLUSION: Delay of microvascular free-flap coverage beyond the previously published three-day protocol may not dramatically affect treatment success.

\section{Le traitement des brûlures électriques par un simple débridement recouvert d'un lambeau libre : La rapidité a-t-elle tant d'importance ?}

HISTORIQUE : Des brûlures électriques de haute tension touchant les extrémités peuvent provoquer une perte marquée des tissus cutanés et sous-cutanés qui exposent l'os et le tendon sous-jacents. D'ordinaire, le traitement des brûlures électriques entraine un débridement sériel et une fermeture tardive de la plaie. Le transfert microvasculaire d'un lambeau libre dans les trois jours suivant la brûlure peut assurer le succès.

OBJECTIF : Sept patients présentant des brûlures électrique de haute tension sont présentés. L'application et le moment de la couverture par lambeau libre sont exposés.

RÉSULTATS : Les lambeaux libres ont guéri chez six des sept patients. CONCLUSION : Le retard de la couverture microvasculaire par lambeau libre après le protocole limité à trois jours préconisé auparavant ne nuirait pas énormément au succès du traitement.

Key Words: Electrical burn; Free-flap; Single debridement; Surgical treatment

Chick et al (1) employed a novel technique in five cases of
single debrical burn. They carried out a regimen of aggressive
days of injury. The timing of treatment in the presented case
series ranged from eight days to seventy-one days. With this
contrast in mind, we attempted to identify complications that
may have arisen from the increased time from injury to treat-
ment in the seven patients identified.

\section{PATIENTS AND METHODS}

A review of burn patients from 1989 through 1999 revealed seven patients that suffered high-voltage (greater than 5000 volts) fullthickness electrical burns. Patients with thermal burns or burns not requiring free-flap surgery were not included in this study. All of the patients were men between the age of 20 and 64 years. All patients were stabilized in the intensive care and burn unit before operative management.

\section{RESULTS}

One patient underwent surgery eight days post-burn, two patients at 10 days, two at 11 days, one at 24 days, and one at 71 days. The operations performed consisted of debridement of skin and subcutaneous tissue according to colour and perfusion, as evidenced by a bleeding wound margin. The debridement spared nerves, tendons and bone as long as they were physically intact, without regard to their presumed functionality. A total of seven free-tissue transfers were carried out.

\section{CASE PRESENTATIONS}

Patient 1 suffered a large full-thickness burn over the plantar aspect of the heel extending over the Achilles tendon, which was exposed. Initially the wound was managed with twice weekly dressing changes. Over the course of two months the wound did not heal; therefore, debridement and coverage was performed with no wound healing complications.

Patient 2 was a 43-year-old man with a past medical history significant for gout and a congenital single kidney that was at the time failing. He suffered a full-thickness burn to the left foot with total devitalization of the lateral four toes, the distal portion of the dorsum of the foot and the lateral ankle. Thirty days after debridement and coverage, the wound continued to appear healthy, and the patient was discharged home. Subsequently, the patient was readmitted for treatment of anemia and an infected left foot. Despite the infection in the

${ }^{1}$ Division of Plastic Surgery, Dalhousie University, Halifax, Nova Scotia; ${ }^{2}$ Department of Plastic Surgery, Loma Linda, California; ${ }^{3}$ Department of Plastic Surgery, Rockyview Hospital, Calgary, Alberta; ${ }^{4}$ Department of Plastic Surgery, Pasqua Hospital, Regina, Saskatchewan

Correspondence: Dr Christopher J Thomson, Division of Plastic Surgery, Dalhousie University, Halifax, Nova Scotia.

E-mail ctthomson@hfx.eastlink.ca 
foot, the flap survived well; however, significant pain caused him to request a below-knee amputation 16 months after the initial surgery.

Patient 3 suffered a full-thickness burn to the right foot over the heel and Achilles tendon. A lateral arm flap healed well, and the patient was discharged home 16 days after the injury.

Patient 4 suffered a full-thickness burn to the medial aspect of the left foot. A radial forearm flap healed without complications and the patient was discharged home four weeks after the injury.

Patient 5 suffered full-thickness burns to the right foot. A lateral arm flap healed without complication and the patient was discharged one week after the surgery.

Patient 6 suffered full-thickness burns to the right foot. His past medical history was significant for cardiac arrhythmia; thus, he was managed intensively by the internal medicine department until completely stable. The lateral arm flap appeared to become slightly congested postoperatively. Leech therapy was started and the congestion resolved. The patient was discharged home 10 days after the initial injury.

Patient 7 suffered a full-thickness burn to the right foot. A lateral arm flap appeared healthy for two weeks, but over the third week it began to darken and appeared necrotic. He was thought to have developed a delayed distal occlusion and fistula within the flap that caused the superficial portion to become necrotic. Subsequent debridement revealed that the deeper aspect of the flap was healthy; thus, a split-thickness skin graft was applied. This graft had 100\% take and the patient was discharged eight days later.

\section{DISCUSSION}

Building on previous experience with early free-flap coverage of traumatic wounds (2), Chick et al (1) reported five cases of electrical burns treated with a single debridement followed by free-flap coverage. They followed a protocol that dictated debridement and coverage should be undertaken within three days of the injury whenever possible $(3,4)$.

The three-day protocol used was based on the experience of Godina (3) in the field of early reconstruction of complex orthopedic trauma to the extremities. In his study, patients were retrospectively segregated into three groups: those treated within seventy-two hours, from seventy-two hours to three months, and from three months to twelve and one-half years. He studied a number of different parameters related to wound healing, including the rates of flap failure, infection, bonehealing time, length of hospital stay and number of operative procedures. In all categories studied, the patients treated within seventy-two hours had superior outcomes.

Godina retrospectively divided his treatment groups in a completely random manner. The seventy-two hour dividing line between groups 1 and 2 was not based on any existing evidence of a difference in wound-healing potential between these two groups. It was simply a convenient time frame that most readers would agree could be considered 'early treatment'. The question left unanswered is: what is the true amount of delay in treatment that causes increased rates of complication? Secondly, the time frame chosen to represent groups 2 and 3 is as arbitrary as the seventy-two hour point in time. Group 2 encompasses those patients treated from seventy-two hours to three months. Does this represent a truly homogeneous population of patients? Group 2 may in fact encompass two or more populations of patients with respect to their propensity for wound-healing complications. If the second group were subdivided into seventy-two hour intervals, it might be found that the complication rate steadily rises in proportion to delay in treatment, and the complication rate quoted is merely an average of many different populations. Therefore, the increased rate of wound-healing complications reported in patients receiving treatment between seventy-two hours and three months (group 2) when compared with group 1, is based on a completely random designation of the population. Finally, the application of a protocol designed for the treatment of orthopedic trauma to the treatment of electrical burns is of questionable value due to two very different mechanisms of injury. Orthopedic trauma cases are frequently complicated by the presence of significant bacterial and foreign body contamination that serves as a nidus for wound infection complications. Due to the heat generated during the injury process, electrical burns are considered to be clean wounds with less potential for infection.

\section{CONCLUSION}

The surgical technique employed by Chick et al (1) is undoubtedly a very useful one. However, the application of Godina's (3) seventy-two hour deadline is of questionable value when the design flaws and radically different mechanism of injury of this landmark study are taken to account. The mean time between injury and free-flap transfer in this case series was 21 days. The increase in time from injury to treatment does not appear to have had a significant effect on treatment outcome. The cases presented call into question the need for coverage of wounds within seventy-two hours. This finding may allow the surgeon more latitude in deciding when a patient is fit to undergo operative treatment after a major electrocution accident.

\section{REFERENCES}

1. Chick LR, Lister GD, Sowder L. Early free-flap coverage of electrical and thermal burns. Plast Reconstr Surg 1992;89:1013-9.

2. Lister G, Scheker L. Emergency free flaps to the upper extremity. J Hand Surg 1988;13A:22-8.

3. Godina M. Early microsurgical reconstruction of complex trauma of the extremities. Plast Reconstr Surg 1986;78:285-92.

4. Jones NF, Lister G. Free skin and composite flaps. In: Green DP, ed. Green's Operative Hand Surgery. Philadelphia: Churchill Livingstone, 1993:1159-200. 